\title{
The Level of Job Burnout Among the Faculty Members of the Private Jordanian Universities in Jordan and the Effect of Gender and Experience Variables on It
}

\author{
Rami I. Al-Shoqran ${ }^{1}$, Awad Mohammad Alfandi ${ }^{2}$, Nusaiba Ali Almousa ${ }^{1}$, Muhannad K. Al-Shboul ${ }^{1}$, Sami \\ Mohsen Katatneh ${ }^{3}$ \& Raeda Mofid Ammari ${ }^{1}$ \\ ${ }^{1}$ Amman Arab University, Jordan \\ ${ }^{2}$ Ministry of education, UAE \\ ${ }^{3}$ Mutah University, Jordan \\ Correspondence: Rami I. Al-Shoqran, Amman Arab University Jordan, Jordan. E-mail: ramishogran@aau.edu.jo
}

Received: July 23, 2020

doi:10.5539/ies.v14n4p83
Accepted: January 13, $2021 \quad$ Online Published: March 28, 2021

URL: https://doi.org/10.5539/ies.v14n4p83

\begin{abstract}
This study aimed to reveal the level of burnout among the faculty members in private universities in Jordan and the effect of gender and experience variables on it. The researchers used the descriptive analytical method. The study was applied to a random sample of (203) faculty members, who were chosen through a comprehensive survey method, with (169) males and (34) females. A job burnout questionnaire was developed, and its validity and reliability were verified. The results of the study showed that the mean of the job burnout of the total degree came with a high degree. The results also showed that there were no statistically significant differences in the level of job burnout of the total degree attributed to the gender variable and in favor of females. Moreover, the results showed that there were apparent differences in the arithmetic averages on the total score for the level of job burnout with different levels of experience variable, and in favor of those with less than five years of experience.
\end{abstract}

Keywords: job burnout, faculty members, private universities

\section{Introduction}

The concept of job burnout is a relatively recent concept and it has been addressed by many researches in the field of social psychology and occupational psychology. This concept assured in its entirety that it represents important work-related problem. To be familiar with it, it requires an understanding of each individual's personality and work environment. Because of the exposure to these problems for a long time, the individuals generate a feeling of pressure, as perhaps during this period they did not receive the necessary support from those who are close, so they feel that they are burnt and there is no solution for them to get rid of these feelings. Psychological burning results when the individual is not able to adapt to psychological pressures, which is reflected in his performance by work and his psyche.

\section{Literature Review}

Job burnout of an individual occurs as a result of his exposure to various psychological pressures that cause him physical, psychological and mental exhaustion, and makes him unable to perform the work and may leave it partially or completely. It represents a state of physical, mental, nervous and emotional stress that occurs as a result of working and interacting with others for a long time and in situations that require emotional exertion, and the emergence of inappropriate attitudes toward clients and towards the self, and is often associated with uncomfortable emotional and physical symptoms, ranging from fatigue and anxiety, to ulcers and migraines, as well as performance degradation. Job burnout occurs when there is an incompatibility between the nature of the work and the nature of the person who is involved in the performance of that work, and the greater the contrast between these two environments, the greater the job burnout that the employee faces in his workplace (Lambie, 2007).

Schaufeli and Peeters (2000) believe that job burnout begins when an imbalance arises between an individual's resources and demands, after which a person develops a set of negative attitudes and behaviors, such as a tendency 
to treat service recipients in a mechanical manner, or indifference to satisfy the needs of others. At this stage, the individual makes a distance between him and others in order to protect himself against the stressful social environment. It is an unsuccessful resistance strategy, as it increases pressure and does not reduce it, and increases the severity of personal problems that may arise, thereby reducing the individual's effectiveness in achieving his goals, which reduces his personal achievement. Job burnout results from the psychological imbalance experienced by individuals working in different professions as a result of severe psychological pressures resulting from workloads and requirements; when we describe an individual with burnout, this means that he was enthusiastic about the work and has a strong motivation for achievement and others expect a lot from him, and job burnout includes three main dimensions (Maslck \& Jackson, 1981).

First: emotional stress, which is a general feeling that an individual suffers and feels mental and emotional fatigue, the depletion of his physical and psychological energies, the loss of activity that he previously enjoyed, in addition to the inability to continue doing the work or performing it as required.

Second: Feelings sag are negative feelings that affect a worker or a professional, as helshe takes negative attitudes towards individuals receiving services and care, and includes cruelty and neglect, and may develop into ridicule and lack of interest, and lose human feelings.

Third: A lack of an accomplishment sense, which is the individual's tendency to evaluate himself negatively, his feeling of complete inability to perform the duties required of him, or his feeling of not being able to accomplish it in the required form, and dissatisfaction with the work he accomplishes.

It is necessary to study all aspects related to job burnout in the teaching profession in order to study its effects on others such as family members, co-workers, supervisors and clients; job burnout has a circular and overlapping effect; thereby, affecting the entire individual's behavior at work and at home as well as his personal directions. The functionally burned individuals may face an increase in mental and health problems, feelings of isolation and internal personal problems, which may affect the performance of their work. The symptoms of job burnout are as follows (Pronost \& Tap, 1997):

- Emotional psychological symptoms: It is represented by psychological and nervous fatigue, feeling after complacency, impotence and inferiority, distress, tension and anger, the tendency to justify, neglect and blame others, low sentiment and daydreaming, lack of attention to detail, and frequent forgetfulness.

- Physical symptoms: appear in physical exhaustion, psychological isolation, rapid pulse, stomach pain, body curvature, sleep and blood circulation disorders.

- Social symptoms: They are represented by problems of social relations with others, suppression of feelings, and social isolation.

- Work-related symptoms: It represents in the negative direction towards work, indifference, absence, delay and desire to leave work, feeling monotonous and boredom, poor readiness and willingness to deal with the pressures of work, loss of control over work and production.

Maslak and his colleagues identified a set of institutional organizational factors that would lead to job burnout in some companies, institutions, and entities as follows (Al-Qarni, 2003):

- Work pressure: It is the feeling of employee that he has a lot of burdens and must fulfil them in a very short time, and through limited and scarce resources. It is noted that many institutions and companies have sought in the past decades to rationalize through laying off large numbers of employees and employment, which has resulted in an increase in job burdens on people remaining in the work.

- Lack of positive reinforcement: When an employee puts a lot of effort into his work, which may require additional hours to access creative works without material or moral compensation, this may be another reason for the employee's job burnout.

- Lack of social relations: human is in his nature a social being, who needs to share the concerns and joys of others, and there are some actions that require physical separation in place, and social isolation from others since working is more with devices and computers and inside laboratories and closed offices.

- Injustice: Sometimes the employee bears responsibilities that exceed his ability, and when he breaks them, he is punished. Deficiencies in performance may not be the employee failure, but rather due to the modest hardware capabilities and limited software, and perhaps due to the lack of technical competencies capable of performing the required duties.

- Values conflict: The employee is sometimes among difficult options, as the work may require him to do something does not conform to his values and principles; for example, the employee may have to lie in order 
to get rid of one of the clients, or such other circumstances.

2.1 Explanatory Theories of Job Burnout (Schaufeli \& Peeters, 2000).

First: Freudian theory or psychoanalysis

The theory of psychoanalysis explains job burnout as a result of an individual's stress on the ego for a long time, in exchange for interest in work, which may constitute a continuous effort for the capabilities of the individual with the individual's inability to face those pressures in a proper way, perhaps psychological burning results from the suppression of unacceptable but rather incompatible desires in the components of the personality and results in a conflict between those components that ends in the most extreme stage of job burnout, or it is the result of the loss of the ideal ego and a gap between the ego and the other that related to it and the loss of the individual side of support and assistance that he was waiting for. Some techniques of the school of psychoanalysis can be used to treat job burnout, such as emotional venting.

Second: behavioral theory

Behavioral theory sees that job burnout in the light of the learning process is an abnormal behavior that the individual learns as a result of inappropriate environment conditions, and students do not have an honest motivation to learn, in addition to the pressures of life and their high costs and all of this falls under the environment surrounding the teacher; thus, that environment is inappropriate, and if the learner does not learn acceptable adaptive behaviors, he may learn an abnormal behavior called job burnout.

Third: Existential theory

Existential theory focuses on its interpretation of job burnout on the absence of meaning in an individual's life. When an individual loses the meaning and the significance of his life, he suffers from an existential vacuum that makes him feel the importance of his life, and deprives him of appreciation that encourages him to continue his life, so he does not achieve his goals and thus is subjected to job burnout.

\subsection{Study Problem and Research Questions}

The faculty member is one of the main pillars of the educational process in universities. He spends most of his day with his students, deals with different personalities and lifestyles, and with different abilities, intelligence and learning styles. The thought of administrative and educational indicates that individuals working in the human professions are more exposed to the phenomenon of job burnout in the workplace due to the different work conditions and the duties that necessitate it to make the utmost efforts to achieve the set goals. Hence, all of these conditions would increase the pressures experienced by the faculty member. It may also contribute to a decrease in its scientific and academic productivity. In order for faculty members to fulfil their professional and humanitarian duty in the most complete manner, it was necessary to pay attention to his performance and the relentless pursuit by all sides to work on his psychological stability to ensure his feeling of satisfaction and reassurance. This in return would reflect positively on the performance of his work, as it would increase his productivity, create an atmosphere of comfort and satisfaction that will certainly be reflected on his students to increase their motivation to learn and deepen their love for education and learning. Hence, this study was to know the levels of job burnout among faculty members in order to find out the reality and trying to prevent it from occurring to ensure a comforting work environment in which learning outcomes are achieved, and in which a good citizen is able to supply the labor market and coexist with the requirements of the times.

\subsection{Study Questions}

This study aimed to answer two research questions:

1) What is the level of job burnout among the faculty members at Amman Arab University?

2) Are there statistically significant differences at the level of $(\alpha=0.05)$ in the level of job burnout among the faculty members in the private Jordanian universities attributed to gender and experience variables?

\subsection{The Importance of the Study}

The importance of this study represented in the following:

- To obtain information and results that educational stakeholders are expected to benefit from represented by the department of educational Policies to take into account the results of the study and to enact policies and legislations that protect faculty members from job burnout.

- $\quad$ To provide a tool with suitable psychometric properties that researchers and interested people can use.

\subsection{Definitions of the Study Terms}




\section{Job burnout:}

It is the state of psychological, mental and physical stress that a faculty member may reach. It is overshadowed by the character of continuity and the formation of negative attitudes towards his profession. In the current study, it is measured by the degree to which the member gets a job burnout scale.

\section{Previous Studies}

The researchers reviewed some studies relating job burnout as following:

The study of Bourzik (2018) aimed to reveal the level of job burnout among teachers with special needs and to know the differences between the genders as well as to know the level of job burnout among them in term of experience. The study sample consisted of (40) participants, in which they divided into (19) female participants and (21) male participants who were chosen from the cities of Laghouat and Guelph in Algeria. This study relied on a Maslash psychological burnout scale. The study revealed that there was a moderate level of job burnout among teachers with special needs. The results also showed that there were no statistically significant differences for the teachers attributed to the gender and experience variables.

Al-Arayda's (2016) study examined the level of psychological burnout among special education teachers in government schools in Al-Rass Governorate in the Kingdom of Saudi Arabia, and their relationship to some demographic variables represented in: teacher experience, type of specialization, educational stage, and the number of students in the classroom. The sample of the study consisted of (32) teachers who were chosen in a similar way from public schools in Al-Rass Governorate during the second semester of the academic year 2013/2014. The results of the study indicated that the psychological burning of the special education teacher Al-Rass governorate was moderate. The outcomes also showed that there were no statistically significant differences attributed to the variables of experience, specialization, grade level, and the number of students in the class.

In the same vein, Al-Hatami (2014) carried out a study aimed to identify the level of psychological burnout among Omani teachers in Al-Dhahirah Governorate. He also intended to discover the relationship between the methods of confronting problems, the level of psychological burnout for teachers, the relationship between the type of education, gender, educational qualification and years of experience number, as well as the level of psychological burnout for teachers. The study sample consisted (84) male teachers and (137) female teachers who were chosen randomly. The results of the study highlighted that the general level of psychological burnout of teachers and the level of using problem-solving methods among Omani teachers in Dhahirah Governorate were moderate. The results also revealed that there was no statistically significant relationship between psychological burning at the dimensions of lacking of the sense of personal achievement and methods to address problems.

Al-Salkhi (2013) performed a study aimed at identifying the levels of psychological burnout among Islamic education teachers in private schools in Amman in the light of the variables of gender, educational qualification, and years of experience number, monthly income, age, marital status, and stage taught by the teacher. The study was applied to a random sample consisted of (166) male and female teachers using the Maslach (1982) scale for psychological burnout. The results illustrated that the level of psychological burnout among the teachers of Islamic education was moderate according to Maslach criteria for psychological burnout on both dimensions emotional stress, feelings sag, and a lack of accomplishment sense dimension was high. The findings also showed that there was a statistically significant difference in the level of psychological burnout on the dimension of emotional stress in favor of males. However, there were no statistically significant differences in the level of psychological burnout according to the age of the teacher, his social condition; teachers with higher educational qualifications, years of long experience, and high monthly income were the most effective on Psychological burning. Moreover, the results showed that there were statistically significant differences attributed to the variable of the teaching stage, and in favor of the basic stage.

Ayasrah (2013) attempted a study aimed at knowing the levels of psychological burnout among male and female teachers in the Education Directorate in Jerash Governorate in Jordan in light of some variables. The sample of the study consisted of (500) male and female teachers chosen randomly from the study population. The results of the study showed that the level of psychological burnout among male and female teachers was high on the level of frequency and intensity and there were also statistically significant differences at the level of $\alpha \leq 0.05$ on the dimensions of the psychological burnout scale, the frequency of lack of achievement sense and the intensity of feelings sag among teachers attributed to the gender variable and in favor of males teachers. On the dimensions of the frequency of feelings sag and the lack of accomplishment sense attributed to the income variable and in favor of teachers with income (300) dinars or less. On the dimensions of emotional stress frequency and intensity, they were attributed to the variable of number of classes and in favor of teachers whose number of weekly classes was 
more than (18) classes. On the dimensions of emotional stress frequency and intensity and Frequency and intensity of feelings were attributed to the place of residence in favor of teachers who work in places far from their residence. In addition, a positive correlation was found with a statistically significant level at $(\alpha \leq 0.01)$ between the frequency and intensity of the emotional stress dimension and between the frequency and intensity of emotional stress dimension and the frequency and dimension of the lack of achievement sense and intensity.

A study performed by Jarrar (2011) aimed at revealing the effect of the variables of gender, educational qualification, administrative experience, monthly salary, school location, number of students, and the major in Bachelor's in the level of psychological burnout. The sample of the study consisted (121) male and female principals in the governorates of the northern West Bank. The results of the study revealed that the level of psychological burnout among government secondary school principals came moderate on the dimensions of emotional stress and feelings sag towards others, while it came low on the dimension of the lack of achievement sense.

Abu Masoud (2010) illustrated, in his study, the extent of the spread of the phenomenon of psychological burnout among the administrative staff working in the Ministry of Education in the Gaza Strip and to determine the relationship between the phenomenon of psychological burnout and a set of demographic factors (gender - age salary - educational qualification - administrative title) - Social status). The study population consisted (258) employees. The researcher used a three- part questionnaire. The first part related to the personal characteristics. The second part was a scale of psychological burnout. The third part was a source of psychological burning. The results also showed that the administrative staff working in the Ministry of Education in the Gaza Strip suffered from a moderate level of psychological burning on both dimensions of psychological stress, and inhumanity, while the level of burnout came low on the dimension of personal achievement.

Similarly, Baqi (2010) conducted a study aimed at measuring the level of psychological burnout and prevailing personality patterns among the teachers of the first three grades working in the Irbid educational area affiliated to UNRWA. It also aimed to reveal the relationship between emotional intelligence, personality patterns and psychological burnout, and the extent to which this relationship differs according to gender, experience and educational qualification. The sample of the study consisted (122) male and female teachers, who were chosen randomly and through the available way. The study population was (231) male and female teachers. The researcher used three measures, the first one was to measure emotional intelligence, the second one was to measure personality patterns, and the third one was to measure psychological burnout. The results of the study showed that the emotional intelligence was high and the psychological burnout was low as well as the diastolic personality pattern among the sample members were dominant. The results also showed a statistically significant positive relationship between emotional intelligence and psychological burnout attributed to gender and educational qualification variables, and between emotional intelligence and personality patterns attributed to gender and experience variables.

Al-Dhafari and Al-Qaryouti's (2010) study aimed to reveal the levels of psychological burnout among teachers of students with learning difficulties in the Sultanate of Oman and the extent of difference for these levels according to the variables of specialization, educational qualification, and social status of female teachers. It also aimed to reveal the relationship between psychological burnout and teaching experience, teacher training courses, and economic levels of school students. The sample consisted (200) female teachers from the first cycle of basic education in the Sultanate of Oman. The researchers used the Maslak and Jackson scale of psychological burnout in its three dimensions: emotional stress, feelings sag, and lack of achievement. The results of the study indicated that the psychological burning among the study sample was low and that the levels of psychological burnout varied according to specialization and in favor of scientific majors, academic qualifications and in favor of the holders of bachelors compared to the holders of higher diploma. While the results did not show statistically significant differences attributed to the social condition of the teacher, and most dimensions of psychological burnout were not related to teaching experience and training courses.

DeVito (2009) conducted a study aimed to reveal the relationship between emotional intelligence and psychological burnout among public high school teachers in New York. The study sample consisted (64) male and female teachers. The researcher used emotional intelligence scale and Maslash measure of psychological burnout. The results of the study indicated that there was no relationship between total emotional intelligence and the two dimensions of psychological burnout, emotional stress and feelings sag. The results also showed that there were no statistically significant differences in the level of psychological burnout attributed to the variables of age and teaching experience. 


\subsection{The Comments of the Previous Studies}

The current study is similar to the previous studies in its goal, which is detecting job burnout, and differs by the used tool a measure that was developed after referring to theoretical literature and previous studies. It also differs from it since it deals with the category of faculty members at Amman Arab University. The current study has benefited from previous studies in defining the problem of the study, developing and formulating it in a scientific manner, selecting the study sample and the statistical procedures. In addition, discussing the obtained results and linking them to the previous studies' results.

\section{Methods and Procedures}

The researcher used the descriptive analytical methods, being the most appropriate for the nature of the study

\subsection{Sample and Population of Study}

The study population consisted of all faculty members at Amman Arab University who answered the study tool whose numbers were 206.

\subsection{Study Tool}

\subsubsection{Job Burnout Scale}

In order to achieve the objective of this study the scale of Job burnout which is its initial form consisted of (35) item.

1) Validity and Reliability of the Scale

The scale was presented to ten arbitrators with a specialization in education and psychology at the Jordanian universities, where they were asked to express opinions and make observations on the scale, where two items were deleted based on the suggestions of the arbitrators because of they are not suitable for the age stage, thus, the scale is in its final form consisted of (25) items.

In order to verify the reliability of the scale, it was applied to a sample of (25) students from outside the study Sample, two weeks later, the scale was re-implemented and the correlation coefficient between the two applications was calculated at $(0.81)$, which is suitable for the current study. The internal consistency of the Cronbach's Alpha was also calculated for the total score (0.88).

\section{2) Correction of Study Tool}

In order to assure the study outcomes the five-step gradient was used. It is divided as follows: Always (5) degrees, often (4) degrees, sometimes (3) degrees, rarely (2) degrees and never (1) degree. The equation of cyber bullying levels was determined as follows:

(Highest value in gradient - lowest value) $/ 3$

$(5-1) / 3=1.33$

The categories were thus formed as follows:

From (1-2.33) low

From (2.34-3.67) average

From (3.68-5) high

3) Statistical Processors

- $\quad$ To answer the first question, mathematical averages, standard deviations, ranks, and level were used.

- To answer the second question, the following statistical methods were used according to the study variables: t-test of two independent samples according to the gender variable, and the one way ANOVA analysis according to the variables of experience and the educational qualification.

\section{Results and Discussion}

First: Results related to answering the first question: What is the level of job burnout among the faculty members at Amman Arab University?

To answer this question, arithmetical means and standard deviations were extracted, and Table 1 illustrates this. 
Table 1. Mathematical averages, standard deviations, and ranks for teachers' job burnout level

\begin{tabular}{|c|c|c|c|c|}
\hline Number & Item & Mean & $\begin{array}{l}\text { Standard } \\
\text { deviation }\end{array}$ & Degree \\
\hline 23 & I feel like I was an introvert because of my work pressure & 4.16 & .96 & High \\
\hline 13 & I feel the stress of this profession & 4.15 & .92 & High \\
\hline 18 & My tension increases while going to work & 4.15 & .88 & High \\
\hline 10 & I feel emotionally drained & 4.13 & .88 & High \\
\hline 6 & I deliberately go to work late & 4.11 & .95 & High \\
\hline 24 & I don't have enough time to prepare for the subjects I taught because of the heavy loads & 4.10 & .94 & High \\
\hline 1 & I feel it is difficult to feel relaxed after a day at work & 4.09 & .82 & High \\
\hline 15 & I feel my effort is underestimated & 4.05 & .99 & High \\
\hline 2 & If I find another job, I will quit my job & 4.03 & .85 & High \\
\hline 22 & Work pressure reflects on my relationship with my family & 4.03 & 1.17 & High \\
\hline 17 & Sometimes I have difficulty controlling my emotions & 4.00 & .93 & High \\
\hline 19 & My anxiety level increases as the contract renewal date approaches & 3.94 & .93 & High \\
\hline 20 & I feel I can do better than I am currently without these psychological pressures & 3.91 & .73 & High \\
\hline 4 & I find it difficult to deal calmly with students' emotional problems & 3.89 & 1.01 & High \\
\hline 7 & I feel comfortable when I am absent from work & 3.87 & .71 & High \\
\hline 21 & I feel exhausted because of this profession & 3.87 & .76 & High \\
\hline 3 & I lose my patience when my students do not respond to what I ask of them & 3.78 & .92 & High \\
\hline 5 & I feel heavy burdens & 3.75 & 1.06 & High \\
\hline 25 & I do not sleep well because of the constant thinking & 3.69 & .40 & High \\
\hline 14 & The burdens are increasing day by day & 3.44 & .50 & Moderate \\
\hline 8 & I feel that my relationship with my students has become negative & 3.39 & 1.05 & Moderate \\
\hline 9 & I feel constant fatigue when I wake up & 3.34 & .48 & Moderate \\
\hline 11 & I feel that students blame me for some of the problems they face & 3.34 & .53 & Moderate \\
\hline 12 & I feel that the behavior of my students increases the pressure on me & 3.34 & 63 & Moderate \\
\hline \multirow[t]{2}{*}{16} & I feel low motivation for work & 3.33 & .58 & Moderate \\
\hline & Total degree & 4.09 & .82 & High \\
\hline
\end{tabular}

It is noted from the results of Table 1 that the level of job burnout among the members of the study sample was high, and item (23) came in the first rank, which stated "I feel like I was an introvert because of my work pressure", with a mean of (4.16) and a standard deviation (0.96), item (16) came at the last rank, which stated "I feel low motivation for work" with a mean of (3.33) and a standard deviation (0.82) and with a moderate degree.

This may be attributed to the fact that the faculty members are similar in the circumstances they live within the university environment and they offer almost the same academic courses, and they are required the same administrative duties, the preparation, the activation of evaluation tools, and the preparation of course files. This result differed with the studies (Bourzik, 2018; Al-Arayda, 2016; Al-Rabadi, 2009; DeVito, 2009), which showed that there were no differences attributed to the gender variable. It also differed with the study of (Ayasrah, 2013) in the return of statistically significant differences in favor of males, while it was consistent with the study of (Baqi, 2010).

The differences may be attributed to females; perhaps because of the female's high degree of concentration in work proficiency and the ability to persist in dealing with children and meet their needs at home or college.

The results related to answering the second question: Are there statistically significant differences at the level of ( $\alpha$ $=0.05$ ) in the level of job burnout among the faculty members in the private Jordanian universities attributed to gender and experience variables? 
Table 2. Arithmetic mean and standard deviations for the level of job burnout according to gender and experience

\begin{tabular}{cccc}
\hline Experience & Gender & Mean & Standard deviation \\
\hline \multirow{2}{*}{ Less than 5 years } & Male & 3.58 & 0.39 \\
& Female & 3.78 & 0.39 \\
\hline \multirow{2}{*}{ Less than 10 years } & Male & 3.48 & 0.44 \\
& Female & 3.64 & 0.33 \\
\hline \multirow{2}{*}{ 10 years and more } & Male & 3.49 & 0.31 \\
& Female & 3.49 & 0.31 \\
\hline
\end{tabular}

It is noted from Table 2 that there were apparent differences between the arithmetic averages and to know whether these differences are statistically significant, the binary variance analysis was extracted and Table 3 shows that.

Table 3. The results of the two-way Anova test to examine the significance of the differences between the averages of the level of job burnout according to experience and gender

\begin{tabular}{cccccc}
\hline Source of variation & Sum of squares & Degree of freedom & $\begin{array}{c}\text { Squares } \\
\text { average }\end{array}$ & $\mathrm{f}$ & Significance level \\
\hline Experience & 1.614 & 2 & .807 & 5.518 & .005 \\
gender & .693 & 1 & .693 & 4.738 & .031 \\
Experience $*$ gender & .004 & 1 & .004 & .029 & .865 \\
The error & 29.387 & 201 & .146 & & \\
Total & 2833.058 & 206 & & & \\
Corrected total & 32.420 & 205 & & & \\
\hline
\end{tabular}

The results in Table 3 indicated that there were statistically significant differences at the level of $(\alpha=0.05)$ in the level of job burnout among the faculty members for the total degree attributed to the experience variable, as the value of " $F$ " (5.518) and the values of "F" of the gender variable (4.738), which is statistically significant at ( $\alpha=$ 0.05 ) and in favor of males. To find out to whom the differences attributed according to the different level of experience, a Scheffe test was used for the dimensional comparisons, and Table 4 shows that.

Table 4. Results of Chef's test of dimensional comparisons between the arithmetic averages of the level of job burnout in the field of frequency according to the variable of experience of the teachers of the first three grades

\begin{tabular}{cccccc}
\hline \multirow{2}{*}{ Field } & Experience variable levels & Mean & Less than 5 years & $\begin{array}{c}\text { From five years to less than 10 } \\
\text { years }\end{array}$ & 10 years and more \\
\hline \multirow{2}{*}{ Total } & Less than 5 years & 3.75 & - & $*_{-0.19}$ & $* 0.26$ \\
degree & From five years to less than 10 years & 3.56 & - & 0.07 \\
& 10 years and more & 3.53 & & - \\
\hline
\end{tabular}

It is noted from the results of Table 4 that the differences between the arithmetic averages were attributed to those with experience category "less than five years". The result of this study differed with the studies (Bourzik, 2018; Al-Arayda, 2016; Al-Rabadi, 2009; Al-Dhafari \& Al-Qaryouti, 2010; DeVito, 2009), which showed that there were no differences attributed to the gender variable. Perhaps this difference is attributed to the nature of specialization and the age stage of the study sample, and this result may be explained by the fact that males, especially at the beginning of their experience, have more social pressures. Moreover, the presence of differences in the current study attributed to the variable of experience and in favor of those who have less experience since they try to overcome the emotional stress and the lack of achievement sense because of enthusiasm and not reaching the stage of boredom or despair from the job as well as from the age stage that they deal with, which requires great patience and great effort. In addition to that, this may attribute to the fact that a faculty member with little or medium experience is constantly concerned with the feeling of the emotional effort at the beginning of his and he has many other conditions and requirements of life, along with his constant attempts to prove himself, which increases his daily burdens.

\section{Recommendations}

Based on the findings of the study, the researchers recommend the following: 
- $\quad$ Finding effective and lasting communication channels between faculty members, university officials and departments to identify the main sources of job burnout.

- $\quad$ Reducing the burdens of the faculty, and not involving them in daily administrative burdens that drain their energies and efforts.

\section{References}

Abu Masoud, S. (2010). The phenomenon of job combustion among the administrative staff working in the Ministry of Education and Higher Education in the Gaza Strip-their causes and how to treat them (Master thesis, Islamic University, College of Commerce, Gaza, Palestine).

Al-Arayda, I. (2016). The Level of Psychological Burning of Special Education Teachers. Journal of Psychological Educational Sciences, 2(1).

Al-Dhafari, S., \& Al-Qaryouti, I. (2010). Psychological Burnout for Female Students with Learning Difficulties in the Sultanate of Oman. Jordanian Journal of Educational Sciences, 6(3), 175.

Al-Hatami, S. (2014). Burnout and its relationship to problem-solving methods among Omani teachers in Al Dhahirah Governorate, Sultanate of Oman (Unpublished Master thesis). College of Sciences and Arts, Department of Education and Human Studies.

Al-Khatib, M. J. (2007). Psychological burnout and its Relation to Ego Flexibility among Palestinian Teachers in Gaza Governorates. Third Educational Conference, Islamic University, Gaza, Palestine.

Al-Qarni, A. (2003). Media and Psychological Combustion: A Study of the Level of Professional Pressure in Media Institutions in the Kingdom of Saudi Arabia. King Saud University, Riyadh.

Al-Rabadi, A.( 2009). The levels of psychological burnout among Math education teachers working in public schools in Amman in the light of some variables. Journal of Educational Sciences, 6(40), 34-50.

Al-Salkhi, M. J. (2013). The levels of psychological burnout among Islamic education teachers working in private schools in Amman in the light of some variables. Journal of Educational Sciences, 4(40).

Ayasrah, M. A. A. A. (2013). A study of levels of psychological burnout among male and female teachers in the Jerash Education Directorate in the light of some variables. Journal of Psychological Educational Sciences, $3(3), 36-64$.

Baqi, N. (2010). Emotional Intelligence and its Relationship to Personality Patterns and Psychological burnout among Teachers of the First Three Classes. An-Najah University Journal for Research (Humanities), 25(1).

Bourzik, K. (2018). Job burnout among Special Needs Educators. Journal of Finance and Business Economics, 6.

DeVito, N. (2009).The relationship between teacher burnout and emotional intelligence: A pilot study. Dissertation Abstract International, 70(2), 13-73.

Jarrar, S. A. (2011). Seriousness at work and its relationship to psychological burnout among principals of public secondary schools in the northern governorates of the West Bank (Palestine) (Unpublished master thesis). An-Najah University, Nablus, Palestine.

Lambie, G. W. (2007). The Contribution Ego Development level to Burnout in School Counselors: Implications for professional school counseling. Journal of counseling \& Development, 25(1), 82-88. https://doi.org/10.1002/j.1556-6678.2007.tb00447.x

Maslach, C. (1982). Understanding burnout: Definitional issues in analyzing a Complex "Phenomenon" Job Stress and burnout (pp. 29-40). Ca: Sage.

Maslck, C., \& Jackson, S. (1981). The Management of Experienced Burnout. Journal of Occupational Behaviour, 2, 99-113.

Pronost, A. M., \& Tap, P. (1997). Usure professionnelle et formation en soins palliatifs. In les Cahiers Internationaux de Psychologies Social, 3, 75-86.

Schaufeli, W. B., \& Peeters, M. C. W. (2000). Job stress and burnout among correctional officers: A literature $\begin{array}{lllll}\text { review. International Journal of Stress Management, } & 7(1), \quad 754-760 .\end{array}$ https://doi.org/10.1023/A:1009514731657 


\section{Copyrights}

Copyright for this article is retained by the author(s), with first publication rights granted to the journal.

This is an open-access article distributed under the terms and conditions of the Creative Commons Attribution license (http://creativecommons.org/licenses/by/4.0/). 